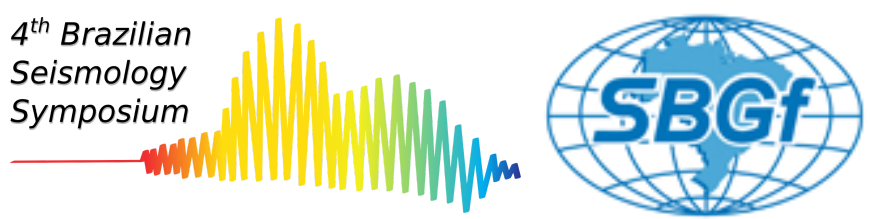

\title{
Observations of some 'exotic' sources by the Brazilian Seismographic Network in NE Brazil
}

\author{
Aderson Farias do Nascimento, Federal University of Rio Grande do Norte \\ José Augusto Silva da Fonsêca, Federal University of Rio Grande do Norte \\ André Tavares da Silva, Federal University of Rio Grande do Norte \\ Eduardo Alexandre de Menezes, Federal University of Rio Grande do Norte
}

Copyright 2021, SBGf - Sociedade Brasileira de Geofísica.

This paper was prepared for presentation during the $17^{\text {th }}$ International Congress of the Brazilian Geophysical Society held in Rio de Janeiro, Brazil, 8-11 November 2021 (Online Event). Contents of this paper were reviewed by the Technical Committee of the $17^{\text {th }}$ International Congress of the Brazilian Geophysical Society and do not necessarily represent any position of the SBGf, its officers or members. Electronic reproduction or storage of any part of this paper for commercial purposes without the written consent of the Brazilian Geophysical Society is prohibited.

Although seismographic networks are primarily designed to record data for earthquake source characterizations or subsurface structure investigation, the continuous waveforms obtained contain serendipitous events from sources related to rock fall events, meteorite impacts, landslides, explosions both intentional and accidental, sinking of ships, social isolation, lightning strikes, aircraft crashes to cite a few. On many occasions the seismographic records from these 'exotic' sources are the only time-series records available. Therefore, seismic analysis of these events (and eventually their subevents) in terms of their energies, durations, frequency content, and localizations can provide important information on how these events initiated and evolved. Additionally, seismic 'exotic' sources provide educational and community engagement opportunities for seismology. Here, we present two meteorite impacts in NE Brazil (on February 172021 in Ceará State and October 28 2013, in Bahia State), and one rock fall event (near Brejo da Madre de Deus, NE Brazil) recorded by some broadband sensors of the Brazilian Seismographic Network. We characterize the seismic signals from these sources and use standard seismological techniques to locate the likely impact locations of the falls, and characterize the recorded wave field. In the case of the rock fall event, we were also able to ground-truth our estimated rock fall location using information provided by the local population that feared the consequences of the phenomenon. We demonstrate that seismic records have the potential to assess the characteristics of these sources and a systematic search of these type of signals is an opportunity for seismic signal analysis, risk assessment and societal engagement with seismology. 